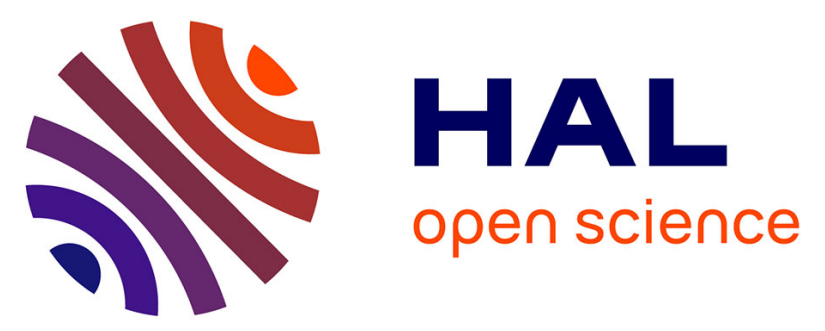

\title{
Tsaap-Notes - An Open Micro-Blogging Tool for Collaborative Notetaking during Face-to-Face Lectures
}

Franck Silvestre, Philippe Vidal, Julien Broisin

\section{To cite this version:}

Franck Silvestre, Philippe Vidal, Julien Broisin. Tsaap-Notes - An Open Micro-Blogging Tool for Collaborative Notetaking during Face-to-Face Lectures. IEEE International Conference on Advanced Learning Technologies - ICALT 2014, Jul 2014, Athènes, Greece. pp. 39-43. hal-01147226

\section{HAL Id: hal-01147226 \\ https://hal.science/hal-01147226}

Submitted on 30 Apr 2015

HAL is a multi-disciplinary open access archive for the deposit and dissemination of scientific research documents, whether they are published or not. The documents may come from teaching and research institutions in France or abroad, or from public or private research centers.
L'archive ouverte pluridisciplinaire HAL, est destinée au dépôt et à la diffusion de documents scientifiques de niveau recherche, publiés ou non, émanant des établissements d'enseignement et de recherche français ou étrangers, des laboratoires publics ou privés. 


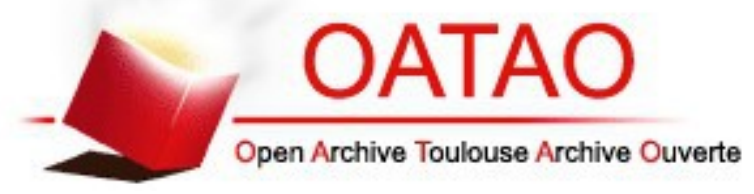

\section{Open Archive TOULOUSE Archive Ouverte (OATAO)}

OATAO is an open access repository that collects the work of Toulouse researchers and makes it freely available over the web where possible.

This is an author-deposited version published in : http://oatao.univ-toulouse.fr/ Eprints ID : 13144

To link to this article : DOI :10.1109/ICALT.2014.22

URL : http://dx.doi.org/10.1109/ICALT.2014.22

To cite this version : Silvestre, Françoise and Vidal, Philippe and Broisin, Julien Tsaap-Notes -- An Open Micro-Blogging Tool for Collaborative Notetaking during Face-to-Face Lectures. (2014) In: IEEE International Conference on Advanced Learning Technologies ICALT 2014, 7 July 2014 - 9 July 2014 (Athènes, Greece).

Any correspondance concerning this service should be sent to the repository administrator: staff-oatao@,listes-diff.inp-toulouse.fr 


\title{
Tsaap-Notes - An Open Micro-Blogging Tool for Collaborative Notetaking during Face-to-Face Lectures
}

\author{
Franck Silvestre, Philippe Vidal, Julien Broisin \\ Institut de Recherche en Informatique de Toulouse \\ University of Toulouse III \\ Toulouse, France \\ \{franck.silvestre,vidal,broisin\}@irit.fr
}

\begin{abstract}
Social theories of learning demonstrated that collaborative notetaking during face-to-face lecture provides important benefits: better learner engagement, collaborative learning, and knowledge building. In this paper we present Tsaap-Notes, an open micro-blogging platform dedicated to collaborative notetaking that can be used as a standalone application, or fully integrated into existing virtual learning environments. Tsaap-Notes provides users with advanced features such as annotations, questions, or filtering that encourage learners to participate in the collaborative activity. Our tool has been experimented with a cohort of forty students during a short period of time; results show that learners are getting more and more familiar with Tsaap-Notes and that this application becomes useful when the time of preparing exams has come.
\end{abstract}

Keywords-notetaking; collaborative learning; open platform; face-to-face lecture; personal response system

\section{INTRODUCTION}

Notetaking is a discipline agnostic activity where learners add personalized contents in reaction to the content delivered by teachers. During face-to-face lectures, learners are used to practice this activity: in the study presented in [19], Steimle et al. show that the proportion of students taking notes during a course varies between $60 \%$ and $95 \%$. Learners most often used to write down their notes on white papers; however, with the development of smart and compact devices connected to Internet, more and more students are equipped with an electronic device during lectures. Therefore, offering them the opportunity to take notes with an efficient tool may be of their interest, especially when they have the opportunity to work collaboratively. Indeed, based on social theories of learning, Kam et al. show in [12] that collaborative notetaking during lecture provides additional benefits: better learner engagement, collaborative learning, and knowledge building. Besides, it offers the opportunity to teachers to deliver prompt feedback. Similar experiences such as the use of a wiki [16], or the use of a collaborative text editor [10], sustain these statements.

Various tools and systems have been designed to offer users, and more especially learners, the opportunity to take and store notes for further reuse. However, these applications can hardly take into account a large audience of learners and, as a result, a few students only participate actively in the collaboration process. On the other hand, existing tools can hardly interoperate with existing learning environments, thus preventing an efficient data mining that could enhance learning outcomes resulting from the notetaking activity.

In this paper we introduce TsaaP-Notes, an open webbased collaborative notetaking tool standing on a microblogging approach and providing users with enhanced features. Tsaap-Notes focuses on three main objectives: (1) to be easily integrated into existing learning systems, (2) to promote learner engagement into collaborative activities, and (3) to be learning analytics ready in order to further provide intelligent functionalities.

The paper is organized as follows: section II reviews some existing notetaking tools in order to point out their strengths and weaknesses; section III presents Tsaap-Notes and focuses on the key principles that guided its design; finally we report on a first experimentation with Master students of the University of Toulouse III before concluding and exposing some future work.

\section{RELATED WORK}

Nowadays notetaking tools offering collaboration features often adopt a shared document oriented approach: a common document is shared among a given community of users and receives all contributions. Based on Google Drive ${ }^{\circledR}$ that is not specifically designed for learning, the Unishared company [21], that provides a collaborative notetaking platform, signed a partnership with the business school "ESCP Europe" in order to promote the use of its tool by all students. Another tool, Livenotes [12], is presented as a system to work collaboratively with small groups of learners. The document sharing approach facilitates the identification of notes related to a learning content, no matter the level of granularity of the learning resource is high or low; according to the teaching methodology, one document may be created for a whole lecture, and/or others may refer to each chapter of this same lecture. Even if this approach has proven its feasibility, it does not suit very well the learning context, and more specifically face-to-face lectures where a large community of users (including teachers and learners) may have to collaborate. The number of documents containing notes may increase very fast and it may become very difficult and time consuming for users to classify notes along with the related learning content. Moreover, [15] states that in practice, to avoid mess in the shared document, only a few 
students contribute to the document for a given lecture. Therefore, some of the benefits of the collaborative notetaking process are reduced: (1) the feedback available to teachers results from a very small part of the audience, thus making it very difficult for them to bring details on relevant misunderstandings; (2) students cannot engage themselves into the collaborative process, resulting in the desertion of the platform by the learners that don't contribute to the document. Another drawback of this approach is that the same view is offered to all users, whatever their preferences and skills are: there is no way for them to extract a personalized view from the document, to select some contributions only and to reject others. Finally, current tools focus on supporting the notetaking process only, they do not provide intelligent functions such as recommendation or automatic feedback that would leverage students' contributions. This approach thus presents too many weaknesses and cannot be reused to build an efficient collaborative notetaking application.

Micro-blogging, that became widely used since the birth of Twitter ${ }^{\circledR}$, acts as a good candidate for collaborative knowledge building and sharing at any time, anywhere, with any device connected to Internet. Therefore, micro-blogging has been experimented in the field of education [1][4][5][6] [9]. In [7], Ebner et al. claim that micro-blogging is an approach promoting implementation of all the seven principles for good practice in undergraduate education exposed in [3]: (1) Encourages contact between students and faculty (2) Develops reciprocity and cooperation among students (3) Encourages active learning (4) Gives prompt feedback (5) Emphasises time on task (6) Communicates high expectations (7) Respects diverse talents and ways of learning. Another study [11] demonstrates the benefits offered by micro-blogging in the learning area: in addition to the benefits of the shared document approach, microblogging allows a large number of students to contribute, to expose their own ideas, and to get feedback about their posts from other learners and/or teachers. Indeed, the teacher can contribute to a given topic by getting a chance to target ideas or assertions matching with student's posts. Besides, the micro-blogging approach offers filtering features allowing each student to select or ignore contributions according to various metadata such as hash tags, mentions and favorites that describe posts and facilitate their classification, sharing and reuse.

However, Twitter ${ }^{\circledR}$ can hardly be used during face-to-face lectures without specific enhancements. First, it is nearly impossible to link a flow of contributions to a small granularity level of the lecture: hash tags can be used to add semantics to a post, but one cannot deduce that a specific tag refers, as an example, to a given slide of a lecture. Another issue is the lack of reusability of posts. Even if actors of a face-to-face lecture agree on an ad-hoc way to express tags that point to a small part of the lecture, filtering of notes related to a given slide, for example, is very time consuming for students: they have to (1) retrieve the tag identifying the specific resource, (2) launch the search matching with the tag, and (3) save the results. Moreover, the search results are not presented along with the matching slide and learners have to switch between applications to get an overview on both the lecture content and the related notes. Finally, metadata describing lecture material cannot be automatically associated to the notes produced by students. As a result and in the perspective of exploiting learning analytics to enhance benefits of the collaborative notetaking process, this loss of semantic data appears very frustrating.

Existing micro-blogging platforms can't be reused natively as full-featured collaborative notetaking systems, but they represent a relevant basis to be enhanced to meet the specific requirements of such applications. We thus adopted this approach to design and implement Tsaap-Notes, and introduced specific education-oriented features.

\section{TSAAP-NOTES}

\section{A. Overview}

Tsaap-Notes (http://notes.tsaap.eu/tsaap-notes) is an open web-based application accessible to anyone from any device connected to Internet (smartphone, computer, tablet PC, etc.). As a standalone application, the system provides the following basic functionalities: a user can access all existing notes, post a new note, reply to an existing note, delete the notes he/she posted, or mark a note as favorite. The size of a note is limited to 280 characters, but a user can post as many notes as needed. Finally, a note may contain hash tags that are used to qualify and index the note, and then reused for filtering purposes (see further in subsection C).

In addition to using the tool as a standalone application, Tsaap-Notes can also be easily integrated into existing virtual learning environments. As an illustration, it has been integrated into a system we started to develop two years ago and that generates, from course material compliant with the OASIS DocBook format, a slide presentation embedded into an HTML page. This full integration appears on Fig. 1 and allows displaying, for each slide composing the lecture, the whole set of notes related to the current slide. The first zone is a navigation bar allowing students to navigate from one slide to another; the second zone displays the content of the current slide; the third zone represents the embedded interface of Tsaap-Notes where students are able to consult existing notes and post as many additional notes as needed. All new notes are linked automatically to the current slide, and characterized by the metadata describing the slide.

Thus, notes appear in this use case as annotations related to a refined part of the whole lecture. This feature is of most importance, since it has been shown in [13] that students achieve maximum retention of lecture material when they annotate content characterized by a low level of granularity.

\section{B. Contextualized notes}

As mentioned earlier, micro-blogging hash tags help users to provide information about the content of a single post. However, this metadata is not powerful enough to simply link a flow of posts to predefined or existing resources; to tackle this issue and to make it easy to contextualize a (flow of) note(s) to a specific learning area or learning resource, we introduced the scope concept. 
A scope relies on any entity, digital or non-digital, which is related to education and learning. It may thus refer to a course, a discipline or a platform, and is characterized by a name, a description that may contain hash tags, and an optional URL pointing to the targeted digital resource (when applicable). When a user consults a scope to display the related notes, his/her notes are linked automatically to this scope and inherit from the hash tags characterizing the scope description. Thus, no efforts are required from users to add semantics to their notes. In addition, a user can subscribe to a scope (using a "Follow/Unfollow" button) in order to be notified when other users post new contributions related to this scope.

The scope concept is useful to exploit Tsaap-Notes from a learning environment that is not specifically designed to fully integrate our tool; let us take a simple scenario. A teacher creates a scope (using the web interface of TsaapNotes) related to a course exposed to his/her students through the well-known learning management system Moodle, and integrates, within this course, a link pointing to the scope he/she just created. Here, notes taken by learners enrolled into the Moodle course are contextualized automatically according to the courseware. Students are then able to easily retrieve all notes related to the course when the time to prepare exams has come, or even select the notes that best suit their needs, as described below.

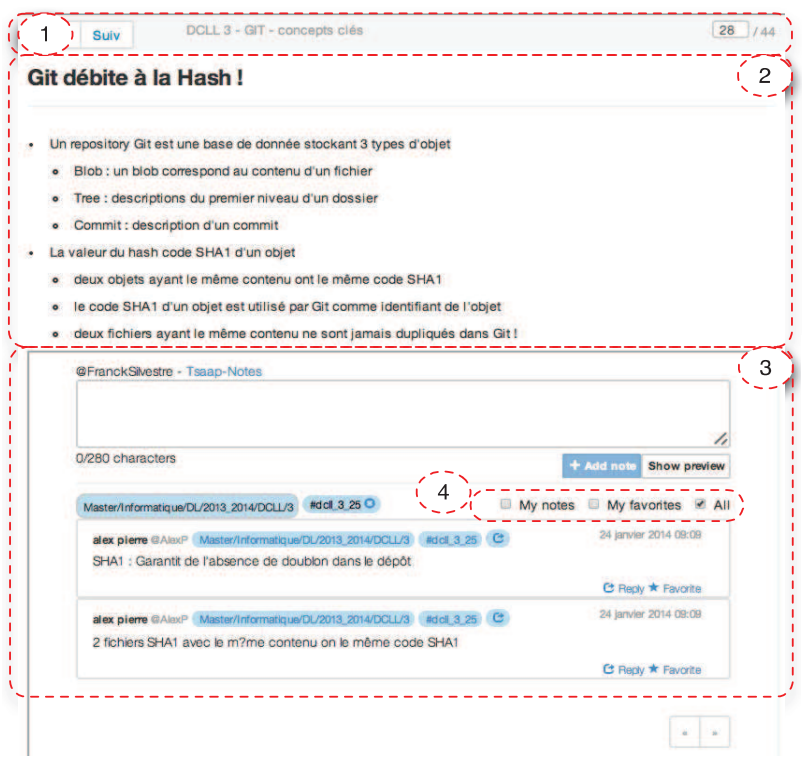

Figure 1. Tsaap-Notes embedded in a web page with a slide

\section{Filtering of notes}

Section II showed that filtering features offered by current micro-blogging tools bring values to the learning perspective. In addition to the scope concept presented above, Tsaap-Notes provides users with the ability to filter a set of notes so that only the notes the user is interested in are displayed. On Fig. 1, the fourth red zone exposes the filtering features: the user can choose to display all notes (related, or not, to a given resource or scope) so that he can mark those that are of most importance as favorite, and/or only the notes he/she posted, and/or only those he/she marked as favorite. These filters thus prevent the mess appearing in shared document oriented applications when the targeted audience of the lecture becomes too large. To strengthen this feature, some work is in progress to provide users with the opportunity of processing faceted filtering based on tags, mentions, favorites, authors and scopes.

Notations, contextualized notes and filtering of notes represent valuable features of collaborative notetaking systems. However, to deeper encourage collaboration of learners and to guide teachers to provide relevant helps, we introduced an additional feature.

\section{Engaging learners}

Results presented in [11] and [12], confirmed by social learning theories, state that reviews by teachers of content provided by students during collaborative notetaking or micro-blogging activities encourage discussions between students, and between students and teachers too. In the context of a face-to-face lecture, the review of notes by teachers may become very difficult and even nearly impossible in case of an important audience. As a result, reviews are performed most often after the lecture, thus reducing the ability for the teacher to engage discussions during lectures.

On the other hand, among the various strategies promoting engagement of learners in a learning process, several experiments show that Personal Response Systems suggest effective activities to motivate students and improve their results [2][8][18][20]. Indeed, answers to questions provide interesting feedback that can be reused to guide discussions during lecture: teachers can identify a specific concept or topic that has been misunderstood by learners and provide them with more detailed information about that topic.

Therefore, to enhance the quality and quantity of interactions occurring between actors during a face-to-face lecture, Tsaap-Notes offers teachers the opportunity to test learners through the "notes as questions" feature that maps a note matching a given format (and formulated using the regular blank field illustrated on the third zone of Fig. 1) to an interactive question. As illustrated on Fig. 2, teachers are given control on the time period when a question should be displayed to students (through the start and stop buttons) so that they can further answer the question (see Fig. 3); results are then displayed to all users (see Fig. 4) when the teacher closes the submission period.

The "notes as questions" feature provides teachers with broader control on the details that discussions between actors participating in the lecture should focus on, together with the right time they should take place. Answers then offer an immediate feedback to both learners and teachers: students can get an idea about the level of knowledge regarding a precise topic or concept, while teachers benefit from a quite objective indicator translating the mastery level of the audience regarding this topic to investigate the relevant details. Tsaap-Notes, in this use case, becomes a facilitator to 
teach and learn using frequent diagnostic assessments. Besides, the introduction of structured data, in addition to the natural language notes, provides relevant input data to build intelligent and personalized functionalities (see last section of the document).

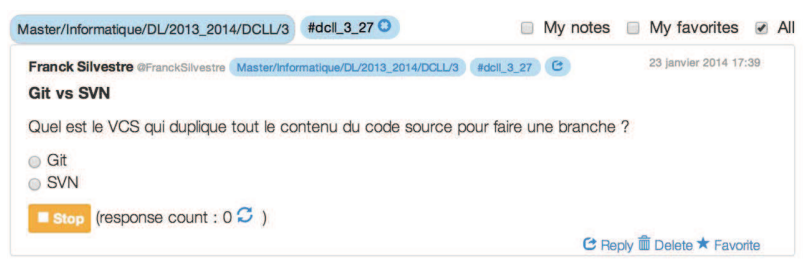

Figure 2. Example of a note as a question

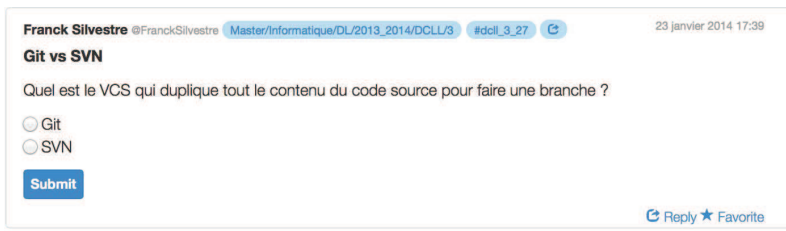

Figure 3. Submission interface

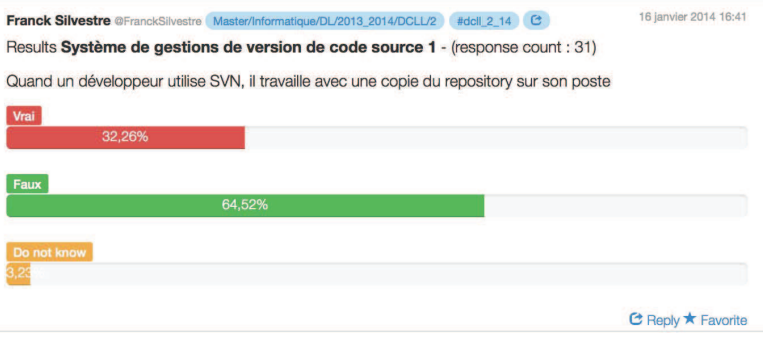

Figure 4. Results display

Let us note that the format used to express a note as a question is based on the GIFT format developed by the Moodle community; therefore a question produced by TssapNotes can be easily integrated into the Moodle server of our university and reused for further evaluation and/or training purposes. The graphical user interface of Tsaap-Notes supports currently single and multiple choices questions, but work are in progress to support additional graphical elements such as drop-down lists.

\section{FIRST EXPERIMENT RESULTS}

Our experiment comprised a cohort of forty (40) students following a Master course on Computer science and focusing on free/open source software and collaborative development. The first part of the course is composed of ten (10) hours of face-to-face lecture, but at the time of writing, four (4) hours have taken place only.

Before the course begins, it was told to students that the use of Tsaap-Notes was optional, and a brief presentation of the tool during about fifteen (15) minutes was made.

\section{A. Quantitative results}

Table 1 exposes statistics about the notetaking activity during the lectures, while Table 2 presents data that help at evaluating the impact of the "notes as questions" feature on the activity of students. The first notable indicator is the number of students who answered the interactive questions: $78 \%$ of the students gave answers, whereas only $25 \%$ of them participated in the collaborative notetaking activity. Secondly, the number of notes taken on slides exposing at least one question represents $65 \%$ of all taken notes. Finally, the number of slides proposing interactive questions represents only $8 \%$ of all slides presented during the lectures. In brief, $65 \%$ of the collaborative notetaking activity is performed over $8 \%$ of slides, those associated with interactive questions.

This first experiment shows that (1) interactive questions during face-to-face lectures promote learner engagement, since most of the students tried to answer the questions, and (2) immediate feedback during the lecture engages students in the notetaking process, since the majority of notes were taken after the presentation of the results of an interactive question.

TABLE I. STATISTICS ABOUT THE COHORT OF STUDENTS

\begin{tabular}{|l|l|}
\hline Count of hours of lectures & 4 \\
\hline Count of presented slides & 62 \\
\hline Count of notes & 23 \\
\hline Count of contributors & $10(25 \%)$ \\
\hline Mean count of notes per student & 0.58 \\
\hline Mean count of notes per contributor & 2.3 \\
\hline Mean count of notes per slide & 0.37 \\
\hline
\end{tabular}

TABLE II. IMPACT OF THE “NOTES AS QUESTIONS" FEATURE

\begin{tabular}{|l|l|}
\hline Mean count of stutents answering question & $32(78 \%)$ \\
\hline Count of notes on slides having question & $15(65 \%)$ \\
\hline Mean count of notes per slide having question & 3 \\
\hline Mean count of notes per slide not having a question & 0.14 \\
\hline Count of slides having question & $5(8 \%)$ \\
\hline
\end{tabular}

B. Qualitative results

Even if the lectures related to this course are not completed yet, we asked students to complete a survey in order to get a qualitative feedback on Tsaap-Notes. At the time of writing, twenty-five (25) students have filled the survey, and Table 3 presents the results obtained on questions where the expected answer is "yes" or "no".

Twenty-two (22) students (over twenty-five) plan to use Tsaap-Notes to prepare their exams, but only seven (7) plan to replay the questions within Moodle. These results show that collaborative notes resulting from interactive questions represent more relevant learning content to students than the questions themselves.

TABLE III. SURVEY RESULTS ON YES/NO QUESTIONS

\begin{tabular}{|l|c|c|}
\hline & Yes & No \\
\hline $\begin{array}{l}\text { Do you plan to use Tsaap-Notes to review } \\
\text { your course before the exam? }\end{array}$ & $22(88 \%)$ & $3(12 \%)$ \\
\hline $\begin{array}{l}\text { Do you plan to replay the interactive } \\
\text { questions within Moodle? }\end{array}$ & $7(28 \%)$ & $18(72 \%)$ \\
\hline
\end{tabular}




\section{TABLE IV. SURVEY RESULTS ON LICKERT SCALE QUESTION}

\begin{tabular}{|l|l|l|}
\hline & \multicolumn{1}{|c|}{ Scale } & Mean \\
\hline $\begin{array}{l}\text { Till now, how would you } \\
\text { qualify your experience with } \\
\text { Tsaap-Notes? }\end{array}$ & $\begin{array}{l}\text { 1 is "very negative", 5 } \\
\text { "is very positive" }\end{array}$ & 3.68 \\
\hline
\end{tabular}

Finally, we asked students to qualify their experience with Tsaap-Notes through a five levels Lickert scale: 1 for "very negative experience", 5 for "very positive experience". The mean value obtained was 3.68. We can consider that the students have globally perceived a good experience using Tsaap-Notes.

\section{CONCLUSION AND FUTURE WORKS}

To improve learner motivation, engagement and results, we presented in this paper an open micro-blogging tool dedicated to collaborative notetaking during face-to-face lectures, and embedding five of the six requirements that such applications should implement [19]: support of annotations (the system offers the opportunity to link a note to a learning content characterized by a high and/or low granularity level) and notes on blank pages (as a standalone application, the system supports notes that are not related to any specific learning content), support of unlimited space (users can post as many notes as needed), support of collaboration (users are able to comment notes taken by other users), and adaptability to a specific context (the system contextualizes a note according to a given discipline or temporal factors); some development efforts have to be leaded to support multi-languages handwritten inputs and to increase adoption of Tsaap-Notes by the growing number of users coming equipped with a tablet PC during lectures. Our tool has been experimented with a cohort of forty (40) students during four (4) hours of face-to-face lecture. The quantitative and qualitative results reveal that students are becoming more and more familiar with Tsaap-Notes and that they plan to review the notes taken by the whole community before the exam.

In order to promote the use of Tsaap-Notes, the main short-term perspective we plan to work on deals with interoperability between our tool and others open web-based learning environments. We want to provide an IMS Learning Tool Interoperability connector so that our tool could be easily and transparently integrated into existing learning systems. This capacity would allow us to make bigger and bigger the amount of notes taken by learners, and thus to investigate how learning analytics functions could be provided by Tsaap-Notes. The studies presented in [8][14][17], based on data mining over micro-blogging oriented platforms, gives good examples of intelligent functions that bring high added value. Indeed, one of the strength of micro-blogging platforms is to allow the analysis of content provided by users, but also the analysis of social network data. Thus, one of our hypotheses guiding our current and future work is that Tsaap-Notes, as microblogging platform designed for learning purposes, is a good candidate to embed learning analytics functionalities such as personalized recommendations, intelligent tutoring, dynamic and personalized questions, or automatic feedback.

\section{REFERENCES}

[1] K. Borau, C. Ullrich, J. Feng, and R. Shen, "Microblogging for language learning: Using twitter to train communicative and cultural competence" in Advances in Web Based Learning-ICWL 2009, 7887

[2] J. Caldwell, "Clickers in the large classroom: current research and best-practice tips." CBE-Life Sciences Education 6.1 (2007): 9-20.

[3] A. Chickering, Z. Gamson, and S. Poulsen, "Seven principles for good practice in undergraduate education" 1987.

[4] D. Davidov, O. Tsur, and A. Rappoport, "Enhanced sentiment learning using twitter hashtags and smileys." in Proceedings of the 23rd International Conference on Computational Linguistics: Posters. Association for Computational Linguistics, 2010.

[5] J. Dunlap, and P. Lowenthal. "Tweeting the night away: Using Twitter to enhance social presence." Journal of Information Systems Education 20.2 (2009): 129-135.

[6] M. Ebner, "Interactive lecturing by integrating mobile devices and micro-blogging in higher education." in Journal of Computing and Information Technology 17.4 (2009): 371-381.

[7] M. Ebner, C. Lienhardt, M. Rohs, and I. Meyer, "Microblogs in Higher Education-A chance to facilitate informal and processoriented learning?" in Computers \& Education, 2010, vol. 55, no 1, p 92-100.

[8] S. Gauci, A. Dantas, D. Williams, et R. Kemm, "Promoting studentcentered active learning in lectures with a personal response system." in Advances in Physiology Education, 2009, vol. 33, no 1, p. 60-71.

[9] G. Grosseck, and C. Holotescu. "Can we use Twitter for educational activities." in 4th international scientific conference, eLearning and software for education, Bucharest, Romania. 2008.

[10] B. Habert, "Notes de cours collaboratives" in http://archinfo02.hypotheses.org/38, 2012.

[11] R. Junco, ,G. Heiberger, And E. Loken, "The effect of Twitter on college student engagement and grades" in Journal of Computer Assisted Learning, 2011, vol. 27, no 2, p. 119-132.

[12] M. Kam, J. Wang, A. Iles, E. Tse, J. Chiu, D. Glaser, O. Tarshish, and J. Canny, "Livenotes: a system for cooperative and augmented notetaking in lectures" in Proceedings of the SIGCHI conference on Human factors in computing systems. ACM, 2005. p. 531-540.

[13] K. Kiewra, N. DuBois, D. Christian, and A. McShane. "Providing study notes: Comparison of three types of notes for review." in Journal of Educational Psychology, 1988, vol. 80, no 4, p. 595

[14] H. Kwak, C. Lee, H. Park, and S. Moon, "What is Twitter, a social network or a news media?" in Proceedings of the 19th international conference on World wide web. ACM, 2010. p. 591-600.

[15] Leo, "Interview Clément Delangue, fondateur Unishared" in http://else-et-esse.fr

[16] M. O'Neill, "Automated use of a wiki for collaborative lecture notes" in ACM SIGCSE Bulletin. ACM, 2005. p. 267-271.

[17] M. Pennacchiotti, and A. Popescu, "A Machine Learning Approach to Twitter User Classification." ICWSM (2011).

[18] D. Shaffer, and M. Collura, "Evaluating the effectiveness of a personal response system in the classroom." in Teaching of Psychology, 2009, vol. 36, no 4, p. 273-277.

[19] J. Steimle, I. Gurevych, and M. Mühlhäuser, "Note-taking in University Courses and its Implications for eLearning Systems" in DeLFI. 2007. p. 45-56.

[20] M. Uhari, M. Renko, and H. Soini. "Experiences of using an interactive audience response system in lectures." BMC Medical Education 3.1 (2003): 12.

[21] Unishared. Available at http://www.unishared.com. 